Pacific Journal of Mathematic 


\title{
ON THE CHANGE OF INDEX FOR SUMMABLE SERIES
}

\author{
Dieter GAIER
}

1. Introduction. Assume we have given a series

$$
a_{0}+a_{1}+a_{2}+\cdots+a_{n}+\cdots
$$

and consider

$$
b_{0}+b_{1}+b_{2}+\cdots+b_{n}+\cdots \text { with } b_{0}=0 \text { and } b_{n}=a_{n-1} \quad(n \geq 1)
$$

denote the partial sums by $s_{n}$ and $t_{n}$, respectively. Since $s_{n}=t_{n+1}$, the convergence of (1.1) is equivalent to that of (1.2). However, if a method of summability $V$ is applied to both series, the statements
(1.3)
(a) $\quad V-\sum a_{n}=s$
(b) $\quad V-\sum b_{n}=s^{1}$

need not be equivalent (for example, if $V$ is the Borel method; see [4, p. 183]). If $V\left(x ; s_{\nu}\right)$ and $V\left(x ; t_{\nu}\right)$ denote the $V$-transforms of the sequences $\left\{s_{n}\right\}$ and $\left\{t_{n}\right\}$, respectively, it is therefore interesting to investigate, for which methods $V$ and under what restrictions on $\left\{a_{n}\right\}$ the relations

$$
\begin{aligned}
\text { (a) } V\left(x ; s_{\nu}\right) \cong K \cdot x^{q} & \text { (b) } V\left(x ; t_{\nu}\right) \cong K \cdot x^{q} \\
& \left(x \longrightarrow x_{0}, K \text { constant; } q \geq 0 \text {, fixed }\right)^{2}
\end{aligned}
$$

are equivalent.

The cases $V=C_{k}$ (Cesàro) and $V=A$ (Abel) are quickly disposed of ( $\$ 2$ ), while $V=E$ (general Euler transform) and $V=B$ (Borel) present some interest $(\S \S 3-5)$.

2. THEOREM 1. The statements (1.4.a) and (1.4.b) are equivalent for

\footnotetext{
${ }^{1}$ We shall always let $\sum_{n=0}^{\infty} a_{n}=\sum a_{n}$.

${ }^{2} x \longrightarrow x_{0}$ through values depending on the method $V$.
}

Received December 1, 1953. This work has been sponsored, in part, by the Office of Naval Research under contract N5ori-07634.

Pacific J. Math. 5 (1955), 529-539 
$V=C_{k}(k>-1)$ and $V=A .^{3}$

Proof. If

$$
S_{n}^{(k)}=C_{k}\left(n ; s_{\nu}\right) \cdot\left(\begin{array}{c}
n+k \\
n
\end{array}\right)
$$

and

$$
T_{n}^{(k)}=C_{k}\left(n ; t_{\nu}\right) \cdot\left(\begin{array}{c}
n+k \\
n
\end{array}\right)
$$

we have by definition of the Cesàro means

$$
(1-x)^{k+1} \sum T_{n}^{(k)} x^{n}=\sum b_{n} x^{n}=x \cdot \sum a_{n} x^{n}=x(1-x)^{k+1} \sum S_{n}^{(k)} x^{n},
$$

the series being convergent for $|x|<1$. The proof of Theorem 1 now follows from the inner equality in $(2.1)$ and the relation

$$
\frac{T_{n}^{(k)}}{\left(\begin{array}{c}
n+k \\
n
\end{array}\right)}=\frac{S_{n-1}^{(k)}}{\left(\begin{array}{c}
n+k \\
n
\end{array}\right)} \cong \frac{S_{n-1}^{(k)}}{\left(\begin{array}{c}
n-1+k \\
n-1
\end{array}\right)}
$$

3. Let $g(w)=\sum \gamma_{n} w^{n}$ be regular and schlicht in $|w| \leq 1$, and assume $g(0)=0, g(1)=1$. Then the $E$-transforms of $\sum a_{n}$ and $\sum b_{n}$ are obtained by the formal relations [5]

$$
\sum a_{n} z^{n}=\sum a_{n}[g(w)]^{n}=\sum \alpha_{n} w^{n} ; \quad E\left(n ; s_{\nu}\right)=\sum_{\nu=0}^{n} \alpha_{\nu}
$$

$$
(n=0,1, \cdots) .
$$

$$
\sum b_{n} z^{n}=\sum b_{n}[g(w)]^{n}=\sum \beta_{n} w^{n} ; \quad E\left(n ; t_{\nu}\right)=\sum_{\nu=0}^{n} \beta_{\nu}
$$

THEOREM 2. The statements (1.4.a) and (1.4.b) are equivalent for $V=E$.

Proof. First we note that if either

$$
E\left(n ; s_{\nu}\right)=O\left(n^{q}\right) \text { or } E\left(n ; t_{\nu}\right)=O\left(n^{q}\right)
$$$$
(n \rightarrow \infty),
$$

\footnotetext{
${ }^{3}$ For $q=0$ see $[4$, p. 102$]$.
} 
then the formal relations (3.1) are actually valid for $|w|<1$ and also

$$
\begin{array}{r}
\sum \beta_{n} w^{n}=\sum b_{n}[g(w)]^{n}=g(w) \cdot \sum a_{n}[g(w)]^{n}=g(w) \cdot \sum \alpha_{n} w^{n} \\
(|w|<1) .
\end{array}
$$

Denote by $A_{n}, B_{n}, C_{n}$ the partial sums of $\sum \alpha_{n}, \sum \beta_{n}, \sum \gamma_{n}$, respectively. We assume first

$$
E\left(n ; s_{\nu}\right)=A_{n} \cong K \cdot n^{q} \quad(n \rightarrow \infty) .
$$

Then, since by (3.2) $\sum \beta_{n}$ is the Cauchy product of $\sum \alpha_{n}$ and $\sum \gamma_{n}$, we have

$$
E\left(n ; t_{\nu}\right)=B_{n}=\gamma_{n} A_{0}+\gamma_{n-1} A_{1}+\cdots+\gamma_{1} A_{n-1}
$$

and for $n \geq 1$

$$
\frac{B_{n}}{n^{q}}=\frac{\gamma_{n}}{n^{q}} A_{0}+\gamma_{n-1} \frac{1^{q}}{n^{q}} \cdot \frac{A_{1}}{1^{q}}+\cdots+\gamma_{1} \frac{(n-1)^{q}}{n^{q}} \cdot \frac{A_{n-1}}{(n-1)^{q}} .
$$

For the matrix $c_{n \nu}$ in this transformation of the convergent sequence $\left\{A_{n} n^{-q}\right\}$ we have clearly

$$
\lim _{n \rightarrow \infty} c_{n \nu}=0 \quad(\nu=0,1, \cdots)
$$

Furthermore

$$
\sum_{\nu}\left|c_{n \nu}\right|=\sum_{\nu=1}^{n-1}\left|\gamma_{n-\nu}\right| \cdot \frac{\nu^{q}}{n^{q}}+\frac{\left|\gamma_{n}\right|}{n^{q}} \leq \sum_{\nu=1}^{n}\left|\gamma_{\nu}\right| \leq \sum_{\nu=1}^{\infty}\left|\gamma_{\nu}\right|=M<\infty ;
$$

finally we prove

$$
\lim _{n \rightarrow \infty} \sum_{\nu=0}^{n-1} c_{n \nu}=1
$$

For $q=0$ this follows from

$$
\sum_{\nu=0}^{n-1} c_{n \nu}=\sum_{\nu=1}^{n} y_{\nu} \rightarrow g(1)=1 \quad(n \rightarrow \infty)
$$


for $q>0$

$$
\begin{aligned}
\sum_{\nu=0}^{n-1} c_{n \nu} & =\frac{\gamma_{n}}{n^{q}}+\sum_{\nu=1}^{n-1} \gamma_{n-\nu} \cdot \frac{\nu^{q}}{n^{q}}=\frac{\gamma_{n}}{n^{q}}+\sum_{\nu=1}^{n-1} \gamma_{\nu}\left(\frac{n-\nu}{n}\right)^{q} \\
& =\frac{\gamma_{n}}{n^{q}}+\sum_{\nu=1}^{n-1} C_{\nu}\left[\left(\frac{n-\nu}{n}\right)^{q}-\left(\frac{n-\nu-1}{n}\right)^{q}\right],
\end{aligned}
$$

and the last term is a positive regular transformation of the sequence $\left\{C_{n}\right\}$ tending to $g(1)=1$, whence

$$
\sum_{\nu} c_{n \nu} \rightarrow 1
$$

Therefore the transformation (3.3) of $\left\{A_{n} n^{-q}\right\}$ converges to $K$, which proves $B_{n} \cong K \cdot n^{q}(n \rightarrow \infty)$.

Assume on the other hand $B_{n} \cong K n^{q}(n \longrightarrow \infty)$. Putting $w=0$ in (3.2), one obtains $\beta_{0}=0$, so that

$$
\sum a_{n} w^{n}=[g(w)]^{-1} \sum \beta_{n} w^{n}=w[g(w)]^{-1} \sum \beta_{n+1} w^{n}
$$

is regular in $|w|<1$. Furthermore the expansion of the function $w[g(w)]^{-1}$ for $w=1$ converges absolutely to 1 , since $w=0$ is the only zero of $g(w)$ in $|w| \leq 1$. An argument similar to the one above shows then that $B_{n+1} \cong K_{n} q$ $(n \rightarrow \infty)$ implies $A_{n} \cong K n^{q}(n \longrightarrow \infty)$, which completes the proof of Theorem 2.

We add a few remarks about the assumptions on the function $z=g(w)$ by which the $E$-method is defined.

a. Theorem 2 becomes false if only regularity of $g(w)$ in $|w|<1$, and continuity and schlichtness in $|w| \leq 1$ are assumed. For there exist such functions $g(w)$ whose power series do not converge absolutely on $|w|=1$ ( $c f .[2]$ ). Therefore in (3.2) one could find a convergent $\sum \alpha_{n}$ whose transform $\sum \beta_{n}$ diverges.

b. All that was used about the function $g(w)$ in the proof of Theorem 2 was that the power series of $g(w)$ and of $w[g(w)]^{-1}$ converge absolutely to the value 1 for $w=1$. This can be guaranteed by the weaker assumption that $g(w)$ with $g(1)=1$ and $g(0)=0$ is regular in $|w|<1$, continuous and schlicht 
in $|w| \leq 1$, and that the image of $|w|=1$ under the mapping $g(w)$ is a rectifiable Jordan curve. Because then

$$
\int_{0}^{2 \pi}\left|g^{\prime}\left(e^{i \phi}\right)\right| d \phi<\infty
$$

and hence $\sum\left|\gamma_{n}\right|<\infty[8$, p. 158]; on the other hand also

$$
\int_{0}^{2 \pi}\left|G^{\prime}\left(e^{i \phi}\right)\right| d \phi<\infty
$$

where

$$
G^{\prime}(w)=\left[\frac{w}{g(w)}\right]^{\prime}=\frac{g(w)-w g^{\prime}(w)}{[g(w)]^{2}}
$$

so that also the power series of $G(w)$ converges absolutely to the value 1 for $w=1$.

c. If

$$
g(w)=w[(p+1)-p w]^{-1} \quad(p \geq 0, \text { fixed })
$$

one has $E=E_{p}$ as the familiar Euler method of order $p$, for which Theorem 2 is known in the case $q=0[4, p .180]$.

d. The function

$$
g(w)=(2-w)-2(1-w)^{1 / 2} \quad(g(0)=0)
$$

leads to the method of Mersman [6], as Scott and Wall showed [7, p. 270]. Here Theorem 2 is also applicable, since the more general conditions about $g(w)$ in remark (b) are satisfied, as is readily seen.

4. The Borel method is defined by the transformation

$$
B\left(x ; s_{\nu}\right)=e^{-x} \sum \frac{s_{\nu} x^{\nu}}{\nu !} \quad(x \geq 0)
$$

where the power series is assumed to define an entire function. It is known that $B\left(x ; s_{\nu}\right) \rightarrow K(x \rightarrow \infty)$ implies $B\left(x ; t_{\nu}\right) \rightarrow K(x \rightarrow \infty)$, but not conversely $[4$, p. 183]. We now prove more generally 
THEOREM 3. The relation

$$
B\left(x ; s_{\nu}\right) \cong K x^{q}
$$

implies

$$
B\left(x ; t_{\nu}\right) \cong K x^{q}
$$

Proof. We have for $x>0[4, p .196]$

(4.1) $\quad x^{-q} B\left(x ; t_{\nu}\right)=x^{-q} e^{-x} \sum \frac{t_{\nu} x^{\nu}}{\nu !}=x^{-q} e^{-x} \sum \frac{s_{\nu} x^{\nu+1}}{(\nu+1) !}$

$$
=x^{-q} e^{-x} \int_{0}^{x} \sum \frac{s_{v} t^{\nu}}{\nu !} d t=x^{-q} \int_{0}^{x} e^{-(x-t)} t^{q} \frac{B\left(t ; s_{\nu}\right)}{t^{q}} d t
$$

This transformation of the convergent function $B\left(t ; s_{\nu}\right) t^{-q}(t \rightarrow \infty)$ by means of the 'matrix'

$$
c(x, t)=e^{-(x-t)}\left(\frac{t}{x}\right)^{q} \quad(0 \leq t \leq x)
$$

is regular, since

$$
\int_{t_{1}}^{t_{2}}|c(x, t)| d t \rightarrow 0 \quad\left(x \rightarrow \infty ; t_{1}, t_{2}>0, \text { fixed }\right)
$$

and

$$
\int_{0}^{x}|c(x, t)| d t=\int_{0}^{x} c(x, t) d t=e^{-x} \int_{0}^{x} e^{t}\left(\frac{t}{x}\right)^{q} d t \rightarrow 1 \quad(x \rightarrow \infty)
$$

Therefore $B\left(x ; t_{\nu}\right) \cong K x^{q}(x \longrightarrow \infty)$.

We discuss now the converse of Theorem 3.

THE OREM 4. The relation

$$
B\left(x ; t_{\nu}\right) \cong K x^{q}
$$




$$
B\left(x ; s_{\nu}\right) \cong K x^{q}
$$

if

$$
\lim \sup \left|a_{n}\right|^{1 / n}<\infty
$$

that is, if the series $\sum_{a_{n}} z^{n}$ has a positive radius of convergence.

Proof. Using (4.1) we have for $x>0$

$$
F(x)=x^{-q} B\left(x ; t_{\nu}\right)=x^{-q} e^{-x} \int_{0}^{x} e^{t} B\left(t ; s_{\nu}\right) d t
$$

Consider now $F(x)$ as function of the complex variable $x$ for $R(x) \geq 1$. Then (4.2) implies $\left|t_{n}\right| \leq M^{n}$ for some constant $M>0$ and hence in $\bar{R}(x) \geq 1$

$$
\left|B\left(x ; t_{\nu}\right)\right| \leq e^{-1} \sum \frac{M^{n}|x|^{n}}{n !}=e^{-1+M|x|},
$$

and also

$$
|F(x)| \leq \alpha e^{\beta|x|}
$$

for positive constants $\alpha$ and $\beta$. Hence one knows that

$$
F(x) \rightarrow K \quad(x \rightarrow+\infty)
$$

implies

$$
F^{\prime}(x) \longrightarrow 0
$$$$
(x \longrightarrow+\infty), 4
$$

that is,

$$
\begin{gathered}
x^{-q} B\left(x ; s_{\nu}\right)+\int_{0}^{x} e^{t} B\left(t ; s_{\nu}\right) d t\left[-1-\frac{q}{x}\right] e^{-x} x^{-q} \\
=x^{-q} B\left(x ; s_{\nu}\right)-K+o(1)=o(1) \quad(x \rightarrow+\infty),
\end{gathered}
$$

from which the result follows.

5. We now show that Theorem 4 is best possible in a certain sense.

${ }^{4}$ If $F(x)$ is regular in $R(x) \geq 1$ and (4.3) holds, then $F(x) \rightarrow A(x \rightarrow+\infty)$ implies $F^{\prime}(x) \longrightarrow 0(x \rightarrow+\infty)$. This lemma was used also in [3], where Theorem 4 was proved for $q=0$. 
The ore m 5. In Theorem 4 the Condition (4.2) cannot be replaced by

$$
\lim \sup n^{-\epsilon}\left|a_{n}\right|^{1 / n}<\infty \quad(\epsilon>0) .
$$

For the proof we need the following

LEMmA. For every $\beta>1$, there exists an entire function $f(z)$ of order $\beta$ satisfying

$$
f(x) \rightarrow 0 \quad(x \rightarrow+\infty), f^{\prime}(x) \rightarrow 0(x \rightarrow+\infty) \quad(z=x+i y) .
$$

Proof. Put $\alpha=\beta^{-1}$ and consider the Mittag-Leffler function

$$
E_{\alpha}(z)=\sum \frac{z^{n}}{\Gamma(1+\alpha n)},
$$

which is an entire function of order $\alpha^{-1}=\beta$. Let $m$ be the integer with

$$
\frac{\alpha}{1-\alpha} \leq m<\frac{\alpha}{1-\alpha}+1
$$

We first study the derivatives of $E_{\alpha}(z)$ of order $1,2, \cdots, m$ on the line $\arg z=$ $\alpha \pi / 2$ for large $|z|$. For these $z$ (assume for definiteness $|z|>2$ ) one has [1,pp. 272-275]

$$
E_{\alpha}(z)=\frac{1}{2 \pi i \alpha} \int_{L} e^{t^{1 / \alpha}} \frac{d t}{t-z}+\frac{1}{\alpha} e^{z^{1 / \alpha}}
$$

the path $L$ being

$$
\begin{gathered}
t=r e^{-i \phi_{0}}\left(\infty>r \geq 1, \alpha \pi>\phi_{0}>\frac{\pi \alpha}{2}\right), t=e^{i \phi}\left(-\phi_{0} \leq \phi \leq+\phi_{0}\right), \\
t=r e^{i \phi_{0}}(1 \leq r<\infty)
\end{gathered}
$$

$t^{1 / a}$ is the branch which is positive for $t>0$. The $k$ th derivative of the integral part in (5.3) can then be estimated as follows

$\left|\frac{1}{2 \pi i \alpha} \int_{L} e^{t^{1 / \alpha}} \frac{k !}{(t-z)^{k+1}} d t\right| \leq \frac{k !}{2 \pi \alpha|z|^{k+1}} \int_{L}\left|e^{t^{1 / \alpha}}\right| \frac{|d t|}{|1-(t / z)|^{k+1}}$

$$
=O\left(|z|^{-k-1}\right)=o(1) \quad(|z| \rightarrow \infty) \text {, }
$$


since for our values of $z$ one has $|1-(t / z)| \geq \delta>0$ and on the straight line segments of $L$

$$
\left|e^{t^{1 / \alpha}}\right|=e^{|t|^{1 / \alpha} \cdot \cos \phi_{0} / \alpha} \text { with } \cos \frac{\phi_{0}}{\alpha}<0
$$

Therefore

$(5.4)$

$$
\begin{aligned}
& E_{\alpha}^{\prime}(z)=o(1)+\frac{1}{\alpha^{2}} e^{z^{1 / \alpha}} z^{1 / \alpha-1} \\
& E_{\alpha}^{\prime \prime}(z)=o(1)+\frac{1}{\alpha^{3}} e^{z^{1 / \alpha}} z^{(1 / \alpha-1) 2}
\end{aligned}
$$

$$
\begin{aligned}
& E_{\alpha}^{(m-1)}(z)=o(1)+\frac{1}{\alpha^{m}} e^{z^{1 / \alpha}} z^{(1 / \alpha-1)(m-1)} \\
& E_{\alpha}^{(m)}(z)=o(1)+\frac{1}{\alpha^{m+1}} e^{z^{1 / \alpha}} z^{(1 / \alpha-1) m} .
\end{aligned}
$$

Now we consider the function

$$
F(z)=\frac{1}{z}\left[E_{\alpha}^{(m-1)}(z)-E_{\alpha}^{(m-1)}(0)\right]
$$

which is again an entire function of order $\alpha^{-1}$. For $|z| \rightarrow \infty$ on arg $z=\alpha \pi / 2$ we have by $(5.4)$

$$
F(z)=o(1)+\frac{1}{\alpha^{m}} e^{z^{1 / \alpha}} z^{(1 / \alpha-1)(m-1)-1}=o(1)
$$

however

$$
F^{\prime}(z)=o(1)+\frac{1}{\alpha^{m+1}} e^{z^{1 / \alpha}} z^{(1 / \alpha-1) m-1},
$$

and herein $\left|e^{z^{1 / \alpha}}\right|=1$ and $((1 / \alpha)-1) m-1 \geq 0$, so that $F^{\prime}(z) \nrightarrow 0$ $(|z| \rightarrow \infty$ on $\arg z=\alpha \pi / 2)$. For the lemma it is therefore sufficient to take

$$
f(z)=F\left(z e^{i \alpha \pi / 2}\right)
$$


Proof of Theorem 5. Define the $\left\{a_{n}\right\}$ of $(1.1)$ by

$$
f(x)=\int_{0}^{x} e^{-t} \sum \frac{a_{\nu} t^{\nu}}{\nu !} d t=\int_{0}^{x} e^{-t} a(t) d t
$$

with the $f(x)$ of the above lemma and $\beta=(1-\epsilon)^{-1}$. Since $f(x)$ is of order $\beta>1$, so is $a(t)$, and therefore $[1, \mathrm{p} .238]^{5}$

$$
\lim \sup n^{1 / \beta}\left|\frac{a_{n}}{n !}\right|^{1 / n}=e \lim \sup n^{-\epsilon}\left|a_{n}\right|^{1 / n}<\infty
$$

that is, (5.1) is fulfilled. Furthermore

$$
f(x) \rightarrow 0
$$

which is equivalent to

$$
B\left(x ; t_{\nu}\right) \longrightarrow 0 \quad(x \rightarrow+\infty) .
$$

However, in order that

$$
B\left(x ; s_{\nu}\right) \longrightarrow 0
$$$$
(x \rightarrow+\infty),
$$

it would be necessary and sufficient to have [4, pp. 182-183]

$$
e^{-x} a(x)=f^{\prime}(x) \longrightarrow 0 \quad(x \rightarrow+\infty),
$$

which by our lemma is not fulfilled. So we have given an example of a series $\sum a_{n}$ for which $B\left(x ; t_{\nu}\right) \longrightarrow 0(x \longrightarrow+\infty)$ does not imply $B\left(x ; s_{\nu}\right) \longrightarrow 0$ $(x \rightarrow+\infty)$ and for which (5.1) holds.

${ }^{5}$ Prof. Lösch (Stuttgart) suggested to me the relation to the coefficient problem for entire functions.

\section{REFERENCES}

1. L. Bieberbach, Lehrbuch der Funktionentheorie, 2. ed., vol. II, Leipzig, 1931.

2. D. Gaier, Schlichte Potenzreihen, die auf $|z|=1$ gleichmässig, aber nicht absolut konvergieren, Math. Zeit. 57 (1953), 349-350.

3. - Zur Frage der Indexverschiebung beim Borel-Verfahren, Math. Zeit. 58 (1953), 453 - 455.

4. G. H. Hardy, Divergent series, Oxford, 1949. 
5. K. Knopp, Über Polynomentwicklungen im Mittag-Lefflerschen Stern durch Anwendung der Eulerschen Reihentransformation, Acta Math. 47 (1926), 313 - 335.

6. W. A. Mersman, A new summation method for divergent series, Bull. Amer. Math. Soc. 44 (1938), $667-673$.

7. W. T. Scott and H.S. Wall, The transformation of series and sequences, Trans. Amer. Math. Soc. 51 (1942), 255-279.

8. A. Zygmund, Trigonometrical series, Warsaw, 1935.

HARVARD UNIVERSITY 



\section{PACIFIC JOURNAL OF MATHEMATICS}

\section{EDITORS}

\section{H.L. ROY DEN}

Stanford University

Stanford, California

E. HEWITT

University of Washington

Seattle 5, Washington

\section{R. P. DILWORTH}

California Institute of Technology

Pasadena 4, California

* Alfred Horn

University of California

Los Angeles 24, California

\section{ASSOCIATE EDITORS}

\begin{abstract}
H. BUSEMANN
HERBERT FEDERER

MARSHALL HALL
\end{abstract}

\section{P.R. HALMOS}

HEINZ HOPF

ALFRED HORN
R.D. JAMES

BØRGE JESSEN

PAUL LÉVY
GEORGE PÓLYA

J.J. STOKER

KOSAKU YOSIDA
UNIVERSITY OF BRITISH COLUMBIA CALIFORNIA INSTITUTE OF TECHNOLOGY UNIVERSITY OF CALIFORNIA, BER KELEY UNIVERSITY OF CALIFORNIA, DAVIS UNIVERSITY OF CALIFORNIA, LOS ANGELES UNIVERSITY OF CALIFORNIA, SANTA BARBARA MONTANA STATE UNIVERSITY

UNIVERSITY OF NEVADA

OREGON STATE COLLEGE

UNIVERSITY OF OREGON
UNIVERSITY OF SOUTHERN CALIFORNIA STANFORD UNIVERSITY UNIVERSITY OF UTAH WASHINGTON STATE COLLEGE UNIVERSITY OF WASHINGTON

AMERICAN MATHEMATICAL SOCIETY HUGHES AIRCRAFT COMPANY SHELL DEVELOPMENT COMPANY

Mathematical papers intended for publication in the Pacific Journal of Mathematics should be typewritten (double spaced), and the author should keep a complete copy. Manuscripts may be sent to any of the editors. Manuscripts intended for the outgoing editors should be sent to their successors. All other communications to the editors should be addressed to the managing editor, Alfred Horn, at the University of California Los Angeles 24, California.

50 reprints of each article are furnished free of charge; additional copies may be obtained at cost in multiples of 50 .

The Pacific Journal of Mathematics is published quarterly, in March, June, September, and December. The price per volume (4 numbers) is $\$ 12.00$; single issues, $\$ 3.50$; back numbers (Volumes $1,2,3$ ) are available at $\$ 2.50$ per copy. Special price to individual faculty members of supporting institutions and to individual members of the American Mathematical Society: $\$ 4.00$ per volume; single issues, $\$ 1.25$.

Subscriptions, orders for back numbers, and changes of address should be sent to the publishers, University of California Press, Berkeley 4, California.

Printed at Ann Arbor, Michigan. Entered as second class matter at the Post Office, Berkeley, California.

* During the absence of E.G. Straus.

UNIVERSITY OF CALIFORNIA PRESS - BERKELEY AND LOS ANGELES 


\section{Pacific Journal of Mathematics}

\section{Vol. 5, No. $4 \quad$ December, 1955}

Richard Horace Battin, Note on the "Evaluation of an integral occurring in servomechanism theory" ............................. 481

Frank Herbert Brownell, III, An extension of Weyl's asymptotic law for eigenvalues................................. 483

Wilbur Eugene Deskins, On the homomorphisms of an algebra onto Frobenius algebras .................................. 501

James Michael Gardner Fell, The measure ring for a cube of arbitrary dimension ....................................... 513

Harley M. Flanders, The norm function of an algebraic field extension. II ............................................ 519

Dieter Gaier, On the change of index for summable series ............ 529

Marshall Hall and Lowell J. Paige, Complete mappings of finite groups . . . . 541

Moses Richardson, Relativization and extension of solutions of irreflexive relations..................................... 551

Peter Scherk, An inequality for sets of integers .................. 585

W. R. Scott, On infinite groups ........................... 589

A. Seidenberg, On homogeneous linear differential equations with arbitrary constant coefficients ......................................... 599

Victor Lenard Shapiro, Cantor-type uniqueness of multiple trigonometric integrals...

Leonard Tornheim, Minimal basis and inessential discriminant divisors for a cubic field...

Helmut Wielandt, On eigenvalues of sums of normal matrices ... 